\title{
The Mediterranean diet: health, science and society ${ }^{\text {is }}$
}

\author{
Mariette Gerber $^{1 *}$ and Richard Hoffman ${ }^{2}$ \\ ${ }^{1}$ French Food, Environment and Work Safety Agency (ANSES), Cancer Institute, 34298 Montpellier, Cedex 5, France \\ ${ }^{2}$ School of Life and Medical Sciences, University of Hertfordshire, Hatfield, Hertfordshire AL1O 9AB, UK
}

(Submitted 4 March 2014 - Final revision received 27 September 2014-Accepted 31 October 2014)

\section{Abstract}

The Mediterranean diet (MD) emerged as a healthy food regimen long before it could be recognised which nutrients or foods were responsible for its observed benefits, and it was only in the middle of the last century that the first scientific approach 'The Seven Countries Study' appeared. Epidemiological and anthropological studies of the MD converged, first by investigating at single nutrients or foods, then by adopting the more holistic approach of dietary patterns (DP), and now with a molecular approach. These studies resulted in convincing evidence that a MD decreases the risk of all-cause mortality and cardiovascular mortality and incidence. A risk reduction of developing type 2 diabetes is probable. Evidence is less stringent for other metabolic diseases and all cancers but from possible to probable for some cancer sites. Although DP showed that the MD has to be considered in its totality, olive oil could have a specific role. Lifestyle factors such as physical activity for energy balance, outdoor life for vitamin D synthesis and conviviality are also probably partly responsible for the health benefits. The MD is a lifestyle well suited for coping not only with personal health but also with wider societal concerns in relation to environment, public health and economy.

\section{Key words: Mediterranean diet: Dietary patterns: Health benefits: Societal relevance}

The Mediterranean diet (MD) emerged as a healthy food regimen long before it could be recognised which nutrients, or indeed which foods, were responsible for its observed benefits. From the rich picture that anthropologists provided from various Mediterranean countries, biologists and epidemiologists embarked on a long path towards a full understanding of the aetiology of the observed health benefits, first by investigating at single nutrients or foods, then by adopting a more holistic dietary pattern (DP) approach, and this is now being completed with a molecular understanding. Although health and science have always been associated with studies of the MD, other characteristics such as environmental and public health concerns are also important. The present study briefly considers the history of the emergence of the MD as a healthy DP, and this is followed by recent biological and epidemiological evidence for its stronger health benefits, before concluding with a brief discussion of its societal relevance.

\section{Historical context}

The MD was already characterised by the time of ancient Egyptian civilisation as illustrated by a sculpture on the tomb of Ramses II showing the association of cereals, olive trees and vine. However, it was Castelvetro ${ }^{(1)}$, an Italian exiled in England, who in 1634 first mentioned its relationship with health when, complaining about the local population eating too much meat and not enough fruit and vegetables, he praised the MD for a better health. Much later, in the second part of the twentieth century, the Rockefeller Foundation came to Greece and made an unexpected observation: 'a people with good health and impressive longevity living

Abbreviations: DP, dietary patterns; EPIC, European Prospective Investigation into Cancer and Nutrition; EVOO, extra virgin olive oil; MD, Mediterranean diet; MDS, Mediterranean diet score.

* Corresponding author: M. Gerber, fax +33 468456195, email mariette.gerber@sfr.fr

${ }^{2}$ Publication of these papers was supported by unrestricted educational grants from Federación Española de Sociedades de Nutrición, Alimentación y Dietética (FESNAD), International Nut and Dried Fruit Council (INC), International Union of Nutritional Sciences (IUNS), Fundación Iberoamericana de Nutrición (FINUT), Centro de Investigación Biomédica en Red de la Fisiopatología de la Obesidad y Nutrición (CIBERobn) and Centro Interuniversitario di Ricerca sulle Culture Alimentari Mediterranee (Ciiscam). The papers included in this supplement were invited by the Guest Editors and have undergone the standard journal formal review process. They may be cited. The Guest Editors declare that Salas-Salvadó is a nonpaid member of the World Forum for Nutrition Research and Dissemination of the International Nut and Dried Fruit Council. Angel Gil is President of the Fundación Iberomericana de Nutrición, which is a non-paid honorary position. Lluis Serra-Majem is the President of the Scientific Committee of the Mediterranean Diet Foundation and Scientific Director of the CIISCAM (Centro Interuniversitario di Ricerca sulle Culture Alimentari Mediterranee), Universita La Sapienza di Roma which are both non-paid, honorary positions. Goretti Guasch is the Executive Director and Member of the Executive Committee of the International Nut and Dried Fruit Council, which is a paid position. Mònica Bulló declares no conflict of interest. 
in a country deprived of the modern developments present in the US, and eating vegetables floating in oil ${ }^{(2)}$ !'

But it was 10 years later before a scientific approach emerged on the effects of the MD, when in the 1960s Keys et $a l .{ }^{(3)}$ initiated a large ecological study, the Seven Countries Study, with sixteen cohorts in Mediterranean and nonMediterranean countries. This showed for the first time the low mortality rates in countries around the North shore of the Mediterranean (especially Crete). About 10 years later, the (Multinational MONItoring of trends and determinants in CArdiovascular disease) MONICA study was undertaken in Europe with CVD incidence as an end point (this is more relevant than mortality) ${ }^{(4)}$. Lower rates of CHD were observed in Spain and Southern France compared with Northern France and North European countries. In both studies, the Seven Countries Study and MONICA, dietary questionnaires were collected in subgroups of the cohorts and the main food groups typical of the MD were identified. These studies noted that in many regions on the North shores of the Mediterranean, people were eating the same types of food, even though recipes were different. These consisted of plenty of plant foods including whole grain cereals as staple food, vegetables and fruits (fresh or dried) eaten either raw or cooked. Legumes (lentils, chickpeas and beans), nuts (almonds, pistachios, hazelnuts and walnuts), herbs (thyme, rosemary and basil) and spices (nutmeg, cinnamon and saffron) were also consumed. Fish and seafood were frequent in meals, even in rural areas distant from the sea as they were dried or salted. Meat was only present in a few meals, generally for fiestas, and lamb was preferred. Dairy products were also consumed in moderation, often as fresh cheese from the milk of ewes or goats. Even though staple foods (rice, polenta, bulghur or bread), cooking practices, choice of fruits and vegetables, and use of wild herbs were different, there were two common denominators in the diets of Northern Mediterranean countries: olive oil and wine. Olive oil was used in all meals for cooking and salad dressings and wine was regularly drunk with meals in moderate amounts. Thus, nutritionists elaborated the MD model from these comprehensive observations of the traditional food habits (Table 1).

\section{Biology \\ Fatty acids}

The quality of fatty acids is an important nutritional factor in disease prevention, and it was Keys et al. ${ }^{(3)}$ who first proposed that the ratio of MUFA:SFA was the key component

Table 1. The components of the Mediterranean diet

Cereals (whole grain)

Plenty of vegetables and fruits (raw, cooked or dried) and nuts

Legumes (chickpeas, lentils and beans)

Herbs and spices

Fish and seafood (fresh, dried and pickled)

Moderate amounts of meat and dairy products, preferably from small ruminants (goats and sheep)

Olive oil for salad dressing and cooking

Moderate amounts of wine with meals for the health benefits of the MD. Then, after the Lyon Diet Heart Study, $\alpha$-linolenic acid appeared as important for the prevention of post-myocardial infarct death ${ }^{(5)}$. This was explained by the observation that $\alpha$-linolenic acid, when present in sufficient amounts, is an efficient precursor of EPA, and it is EPA that is responsible for the observed benefits ${ }^{(6)}$. Thus, long-chain $n$-3 fatty acids, together with their metabolites (anti-inflammatory leukotrienes), were reported as essential for the prevention of CVD.

More recently, the importance of the SFA carbon chain length was evoked. Whereas C12 to C16 SFA are known to be atherogenic, SFA with a medium carbon chain length (caproic C6, caprylic C8 and capric C10) are directly $\beta$-oxidised in the liver and so are less atherogenic. Caprylic acid is also an inhibitor of the $\operatorname{apoB}^{(7)}$. This is relevant to the health benefits of the traditional MD, as these fatty acids are in higher concentrations in goats and sheep - the main sources of meat and milk in the MD - than in cows ${ }^{(8)}$.

\section{Phenolics}

Due to the rich diversity of plant foods in the MD, there is a high and varied intake of phenolic compounds, including flavonoids and various non-flavonoids such as phenolic acids, stilbenes and lignans. Total polyphenol intake by the Prevención con Dieta Mediterránea (PREDIMED) cohort was recently estimated at 820 (SD 323) mg/d, with coffee, fruits, olive oil and wine being the major sources ${ }^{(9)}$. The importance of phenolics for the cardiovascular benefits of extra virgin olive oil (EVOO) has been shown by comparing olive oils that are high and low in phenolics. For example, olive oil increased HDL-cholesterol level and lowered oxidised LDL-cholesterol level in proportion to the phenolic content of the oil ${ }^{(10)}$, and the European Food Safety Authority has now recognised the importance of olive oil polyphenols for protecting LDL particles from oxidative damage. Phenolics in wine may also help protect individuals against CVD by contributing to the overall antioxidant effects of the MD, especially when the body is under conditions of oxidative stress that occurs after a meal ${ }^{(11)}$.

Although in vitro studies identified phenolics as direct antioxidants, other more likely in vivo targets are now being identified. These include increasing phase II enzymes in order to eliminate xenobiotics such as carcinogens, by repressing molecules involved in proliferation (such as protein kinase $\mathrm{C}$ (PKC), c-Jun and c-Fos), and by inducing apoptosis (caspases). Inhibition by phenolics of the pro-inflammatory transcription factor nuclear factor- $\mathrm{B}(\mathrm{NF}-\kappa \mathrm{B})$, the pro-oxidant transcription factor activator protein 1 (AP-1), and activation of the antioxidant transcription factor NFE2-related factor 2 (Nrf2) may be involved in reducing oxidative stress and lowgrade chronic inflammation and may contribute to the wide ranging benefits of phenolics against chronic diseases ${ }^{(12,13)}$. Consumption of polyphenol-rich olive oil as part of a MD has also been shown to decrease the expression of a number of genes associated with oxidative stress and inflammation $^{(14)}$. Phenolics generally have low bioavailability and low concentrations in the systemic circulation, and this tends 
to confirm that direct antioxidant activity is not their main mechanism of action in vivo ${ }^{(15)}$

A group of phenolics known as secoiridoids (such as oleuropein) and their breakdown products (such as hydroxytyrosol) are found almost exclusively in olives and olive oil and so are of particular interest in relation to observations that EVOO may confer specific benefits as part of a MD (discussed below). One recently reported target for EVOO secoiridoids (and also resveratrol in red wine) is activation of the energy-sensing enzyme AMP-activated protein kinase $^{(16)}$. AMP-activated protein kinase is currently attracting a good deal of attention as it switches on catabolic pathways, such as increased uptake and oxidation of glucose and fatty acids, and this is implicated in decreasing the risk for obesity, type 2 diabetes and some cancers.

More disease-specific mechanisms for phenolics have also been reported including reduced plaque formation by oleuropein aglycone in a mouse model for Alzheimer's disease $^{(17)}$ and anti-diabetic and anti-cancer effects by flavonoids ${ }^{(18,19)}$. Polyphenols in EVOO promote the proteasomal degradation of human epidermal growth factor receptor 2 (HER2) $^{(20)}$, although it has not been established if this is associated with beneficial effects in HER2 + breast cancer. Olive oil (both virgin and non-virgin) was also identified as the major dietary source of lignans in the PREDIMED cohort ${ }^{(9)}$. Lignans act as phyto-oestrogens in the body and were reported to be associated with a reduced risk of breast cancer in post-menopausal women, although it is unclear if additional anti-cancer mechanisms may also be involved ${ }^{(21)}$.

There is now an increased understanding of how crosstalk between phenolics and other nutrients may contribute to disease prevention ${ }^{(22)}$, and this is helping to provide a mechanistic basis for explaining the epidemiological evidence which suggests that it is the overall MD that is most important for its benefits. This is discussed in the next section.

\section{Epidemiology}

\section{Science: the holistic approach}

After the historical studies described above, the Harvard group listed the beneficial foods of the MD and those which were either absent or consumed in moderation ${ }^{(23,24)}$. But the health benefits of individual nutrients or foods were never completely convincing; it is the holistic approach that best captures the evidence ${ }^{(25)}$.

Different epidemiological designs can be used in this holistic perspective: DP and intervention studies using a nutritional approach. Two techniques are commonly implemented to study the relationship between DP and diseases. A posteriori analysis is a principal component analysis that defines DP in a population. These analyses are transformed into summary scores that can be analysed by regression analysis in order to examine the risk of a disease related to the identified patterns. This technique gives information on the effects of a MD only if a sample of the population follows this model. In the a priori model, a predefined score is applied to the nutritional data of a population. With regard to the MD, the
Mediterranean diet score (MDS) of Trichopoulou first described in $1995^{(26)}$, and completed and finalised in 2003 by the introduction of fish intake ${ }^{(27)}$, has been used most often. However, it is apparent that the Trichopoulou score, including the quantitatively and qualitatively typical $\mathrm{MD}$ of the elderly Greeks, was until recently only appropriate for Mediterranean populations, because (1) in the Greek situation, the MUFA:SFA ratio reflects mainly the consumption of olive oil, which is not the case for North European countries or the USA; (2) the median defining fruit and vegetable consumption in the elderly Greek population (vegetables $\geq 500 \mathrm{~g} / \mathrm{d}$, fruits $\geq 350 \mathrm{~g} / \mathrm{d}$ ) is not commonly attained in North European countries or in the USA and therefore the MDS based on the median consumption of these North European countries or the USA may not show a benefit of MD as it did not reflect the typical quantitative characteristics of the MD. Thus, several modifications have been published that adapt the MDS to diverse populations, and in these cases, the health benefits are generally lower than those observed in Mediterranean countries (for a complete evaluation of DP and MD, see Hoffman \& Gerber ${ }^{(28)}$ ).

A few intervention studies ${ }^{(29-32)}$ have implemented a nutritional approach to study the effects of a MD on markers of risk for CVD, with advice for a MD in the experimental group, and either a high intake of SFA, or a prudent diet or an American Heart Association diet as a control group. However, only PREDIMED $^{(31)}$ had a sample large enough and a follow-up that allowed CVD incidence and mortality to be recorded.

The results of these recent approaches constitute a body of studies with convincing levels of evidence with regard to some health effects, namely all-cause mortality and cardiovascular mortality. They also highlight areas requiring further investigation, such as the specific effects of olive oil.

\section{Health: assessing the evidence}

The inference of causality has been a long search for epidemiologists and was initiated by Hill ${ }^{(33)}$. The World Cancer Research Fund ${ }^{(34)}$ has established criteria for levels of evidence very close to Hill's proposal, with the improvement of introducing a hierarchy for assessing the validity of the designs of the studies, with intervention studies and prospective studies placed at the top. Meta-analyses are also of value as long as they include evaluation of heterogeneity, sensitivity and linear response analysis. An intervention study conducted on a representative population brings results that are the closest to demonstrating a causal relationship between an exposure and health. Consistent results of several prospective studies conducted in different populations in different countries also provide a strong level of evidence. Thus, the only studies presented here are those for which there is enough data to support a conclusion with a convincing or probable level of evidence for a relationship with the MD.

\section{Mediterranean diet}

Results are convincing with regard to the effect of a MD on all-cause mortality as illustrated by the meta-analysis of Sofi 
Table 2. Association (fully adjusted Cox hazard ratio (HR)) between Mediterranean diet scores and all-cause mortality and cause-specific mortality (Hazard ratios and $95 \%$ confidence intervals)

\begin{tabular}{|c|c|c|c|c|c|c|c|c|}
\hline \multirow[b]{3}{*}{ Authors } & \multirow{2}{*}{\multicolumn{2}{|c|}{ Study description }} & \multicolumn{6}{|c|}{ Mortality by cause } \\
\hline & & & \multicolumn{2}{|c|}{ All cause } & \multicolumn{2}{|c|}{$\mathrm{CHD}$} & \multicolumn{2}{|c|}{ Cancer } \\
\hline & Population & Adherence score & $\mathrm{HR}$ & $95 \% \mathrm{Cl}$ & $\mathrm{HR}$ & $95 \% \mathrm{Cl}$ & HR & $95 \% \mathrm{Cl}$ \\
\hline $\begin{array}{l}\text { Trichopoulou } \\
\text { et al. }\end{array}$ & $\begin{array}{l}\text { EPIC - Greece. } 22043 \text { subjects } \\
\text { aged } 20-90 \text { years; } 275 \text { deaths }\end{array}$ & MDS & 0.75 & $0.64,0.87$ & 0.67 & $0.47,0.94$ & 0.76 & $0.59,0.98$ \\
\hline $\begin{array}{l}\text { Knoops } \\
\quad \text { et al. }{ }^{(40)}\end{array}$ & $\begin{array}{l}\text { The HALE project. } 2839 \text { North } \\
\text { Europeans and Italians } \\
\text { aged } 70-90 \text { years; } 935 \text { deaths }\end{array}$ & $\begin{array}{l}\text { MDS (corrected for } \\
8368 \mathrm{~kJ} / \mathrm{d} \\
(2000 \mathrm{kcal} / \mathrm{d}) \text { for } \\
\text { women and } \\
10460 \mathrm{~kJ} / \mathrm{d}(2500 \mathrm{kcal} / \mathrm{d}) \\
\text { for men) }\end{array}$ & 0.77 & $0.68,0.88$ & 0.61 & $0.43,0.88$ & 0.90 & $0.70,1.17$ \\
\hline $\begin{array}{l}\text { Buckland } \\
\text { et al. }{ }^{(39)}\end{array}$ & $\begin{array}{l}\text { EPIC - Spain. } 40622 \text { subjects } \\
\quad \text { aged } 29-69 \text { years; } 1855 \text { deaths }\end{array}$ & $\begin{array}{l}\text { rMDS (adjusted for g } \\
\text { of food/8368 kJ, } \\
\text { and olive oil instead } \\
\text { of MUFA/SFA) }\end{array}$ & 0.79 & $0.69,0.91$ & $0 \cdot 66^{*}$ & $0.49,0.89$ & $\begin{array}{l}0.92 \\
0.79 \dagger\end{array}$ & $\begin{array}{l}0.75,1.12 \\
0.61,1.01\end{array}$ \\
\hline
\end{tabular}

EPIC, European Prospective Investigation into Cancer and Nutrition; HALE, Healthy Ageing: a Longitudinal study in Europe; MDS, Mediterranean diet score; rMDS, relative Mediterranean diet score.

${ }^{*}$ CVD.

$\dagger$ Restricted to digestive, breast and prostate.

et $a l^{(35)}$ and further supported by the latest results from the Women's Health Initiative (WHI) study ${ }^{(36)}$ and the Seguimiento Universidad de Navarra (SUN) study ${ }^{(37)}$. Further evidence comes from the Nurses' Health Study and Health Professionals Follow-Up Study ${ }^{(35)}$, although these cohorts had CVD at the beginning of the study ${ }^{(38)}$. The risk reduction is always greater in Mediterranean countries (by 20-30\%) and always greater for cardiovascular mortality than for cancers, as shown in Table 2 for studies that have evaluated both all-cause and cause-specific mortalities $^{(27,39,40)}$. Table 2 also shows the remarkable consistency between different studies and populations for the hazard ratio for all-cause mortality and cardiovascular mortality.

The PREDIMED intervention study best supports a risk reduction effect of the MD on CVD incidence. It has an interesting peculiarity in that there were two experimental groups: one enriched in nuts and the other enriched in EVOO. The control group consumed a low-fat American Heart Association type diet. Compared with the control group, there was a $28 \%$ (95\% CI $0.54,0.96)$ risk reduction in the nut-enriched group and a $30 \%(95 \%$ CI $0.54,0.92)$ risk reduction in the EVOOenriched group after 5 years of follow-up ${ }^{(31)}$. Total mortality over 5 years (Kaplan-Meier) gave a hazard ratio of 0.81 (95\% CI $0.63,1.05 ; P_{\text {trend }}=0.11$ ) for the EVOO group and $0.95\left(95 \%\right.$ CI $\left.0.73,1.23 ; P_{\text {trend }}=0.68\right)$ for the nut group, suggesting an advantage for olive oil consumption ${ }^{(31)}$.

Thus, there is a convincing causal relationship between a DP similar to the traditional MD and overall mortality, and cardiovascular mortality and incidence.

The relationship between type 2 diabetes and the MD has progressed since two early Spanish publications ${ }^{(41,42)}$ and is now supported by the latest results of the PREDIMED study ${ }^{(43)}$, and by two meta-analyses ${ }^{(44,45)}$. Both meta-analyses concluded that there was a benefit provided by MD in reducing the development of type 2 diabetes (0.81, 95\% CI 0.73 , 0.90 and $0.77,95 \%$ CI 0.66, 0.89, respectively). Both analyses had significant heterogeneity, which was explained by either differences in the lengths of follow-up: the longer the length, the larger the risk reduction ${ }^{(45)}$; or in the health status of the cohort $^{(44)}$ : studies conducted on a cohort at CVD or diabetes risk showed the highest risk reduction. Both analyses observed that the risk reduction was nonsignificant in the US studies and significant in European countries, further suggesting greater benefits in Mediterranean countries, and the authors evoked the possible effects of other beneficial factors present in the Mediterranean lifestyle not revealed by the $\operatorname{MDS}^{(28)}$.

Thus, the level of evidence for a risk reduction of type 2 diabetes development is probable.

An interesting question remains to be elucidated: Which factors present in Mediterranean countries, in addition to the diet, are responsible for this beneficial effect?

Effects on cancer incidence are more difficult to elucidate since the best data come from observational prospective studies because of practical and ethical difficulties with intervention studies. Moreover, not only is each cancer type related to different etiological factors but even within a class of cancer there are different characteristics with regard to the risk factors, e.g. breast cancers with or without oestrogen receptors (ER). Several studies have found inverse associations between increasing MDS and cancer risk. These include studies that did not include olive oil in the score such as head and neck cancers ${ }^{(46)}$, hepatocellular carcinoma ${ }^{(47)}$ and gastric cancer $^{(48)}$ and other studies such as for gastric cancer and bladder cancer in smokers, which were analysed with the relative MDS in which olive oil consumption was assessed ${ }^{(49,50)}$. For breast cancer, a risk reduction was observed only when olive oil was present as a single food ${ }^{(51)}$, or using an a posteriori DP including olive oil ${ }^{(52)}$ or when using a MDS applied to a Mediterranean population ${ }^{(53)}$, but not when applied to a non-Mediterranean population ${ }^{(54)}$.

Thus, it is probable that a MD is inversely associated with some cancers. 
As for diabetes, the heterogeneity observed between Mediterranean and non-Mediterranean countries may possibly be explained by factors of the global Mediterranean lifestyle, such as physical activity, high vitamin D synthesis and quality of life, that correlate with the diet in Mediterranean countries

\section{Olive oil}

Although studies are sparse and further studies are required, it is interesting to note that EVOO might have specific effects on some diseases. This is suggested in the PREDIMED intervention study, especially with regard to cardiovascular mortality ${ }^{(31)}$. In a study conducted in Spain, there was a reduction of CVD incidence of $7 \%$ for each increase of $10 \mathrm{~g}$ of olive oil intake per $8368 \mathrm{~kJ}(2000 \mathrm{kcal})$ ingested, especially with EVOO (risk reduction $14 \%)^{(55)}$. In another study on the same population, an intake $\geq 29.4 \mathrm{~g}$ of olive oil $/ 8368 \mathrm{~kJ}$ per d compared with $<14.9$ g of olive oil $/ 8368 \mathrm{~kJ}$ per d decreased the risk of overall mortality by $26 \%\left(P_{\text {trend }}<0.001\right)$ and of CVD deaths by $44 \%\left(P_{\text {trend }}<001\right)^{(56)}$. In the European Prospective Investigation into Cancer and Nutrition (EPIC) Greek cohort, olive oil was associated with a risk reduction of cerebrovascular disease incidence ${ }^{(57)}$. In the latest report on diabetes and the PREDIMED subcohort ${ }^{(43)}$, the group treated with a MD enriched with EVOO had the lowest incidence of diabetes, and a significantly decreased $\mathrm{RR}$ compared with the group on the control diet $(0.60 ; 95 \% \mathrm{CI}$ $0.43,0.85)$. Investigating the effects of olive oil on breast cancer incidence in the Mediterranean cohorts of EPIC, a risk reduction was observed for ER - breast cancers, although the small number of these cancers did not allow for statistical significance $^{(58)}$. In the Three Cities Study, olive oil was associated with a decrease in cognitive impairment ${ }^{(59)}$

Thus, there is some suggestion for a specific role of olive oil in the MD, but further studies towards understanding the precise effects of olive oil and of its specific phenolics are required.

\section{Societal relevance}

\section{Public health}

For a long time, the high lipid content of the MD has created opposition. Lipids represent $37-38 \%$ of the total energy intake in published studies on the MD, which is slightly above the upper limit of $35 \%$ proposed by the Food and Agriculture Organisation (FAO) ${ }^{(60)}$, and almost at the limit of $35-40 \%$ proposed by the French Food Safety Agency ${ }^{(61)}$. Indeed, a MD might be a way to reduce the public health problem of obesity as (1) the glycaemic indices of most of foods (whole grain cereals, vegetables and fruits) in the MD are low, and the glycaemic load of the MD is decreased by the structure of the Mediterranean meal; (2) a high MDS reduces the risk of weight gain with increasing age as shown in the longitudinal SUN study ${ }^{(62)}$; (3) a traditional MD is the best diet for maintaining a healthy weight after a regimen of weight $\operatorname{loss}^{(63)}$

\section{Health economics}

Stroke is a frequent event in people at cardiovascular risk and, in addition to the human suffering it causes, it is an increasing burden on health budgets due to the increasing longevity of European populations. In France, the mean cost of treating a stroke is $€ 17000$, and the total cost to France is $€ 5 \cdot 3$ billion. In 2006, annual direct health care costs associated with CHD were estimated at $£ 3 \cdot 2$ billion in the UK, and the overall cost to the UK economy was nearly $£$. billion ${ }^{(64)}$. Increased longevity is also accompanied by an increased risk of other degenerative diseases (such as Parkinson's and Alzheimer's diseases), and some studies have shown a risk reduction for these diseases in people adhering to a $\mathrm{MD}^{(65,66)}$. Thus, prevention using a MD will save public money.

\section{Environment}

The moderate amounts of meat consumed as part of a MD means less animal-derived greenhouse gas production. Moreover, there is a preference for small ruminants, raised non-intensively, or mono-gastric animals, which produce less methane than beef ${ }^{(67)}$. The large variety of fruits and vegetables maintains biodiversity and promotes polyvalent agriculture as part of sustainable and organic agriculture and reduces contaminants. The recommendation for seasonal local consumption is also a factor that favours energy economy by reducing the need to heat greenhouses and the need to transport produce from southern hemisphere countries. Hence, adherence to a MD might help to develop sustainable agriculture.

\section{Concluding remarks}

It is important to promote the MD in its entirety to include the benefits of olive oil and to respect variety, diversity and other aspects of the MD such as the structure of the meals and their organisation through the day, and without snacking ${ }^{(68)}$. And to remember that it is more than just a diet, there is also a Mediterranean lifestyle with physical activity - which is mainly outdoors and good for vitamin D synthesis, and also wine drunk in moderation with meals for gastronomy and conviviality. Because a MD is good for individuals, for public health, for health economics and for the environment, Mediterranean countries should treasure it and should work to promote it through information to the public and professionals, and by spreading knowledge of food quality and cooking practices. And, on a larger scale, this needs initiatives from public health and agricultural policies.

\section{Acknowledgements}

None of the authors has conflicts of interest.

The authors' contributions are as follows: R. H. was responsible for the Biology section and editing of the article. M. G. was responsible for the other parts of the text. 


\section{References}

1. Castelvetro G (1989) The Fruit, Herbs \& Vegetables of Italy. London: Viking and British Museum of Natural History.

2. Nestle M (1995) Mediterranean diets: historical and research overview. Am J Clin Nutr 61, 1313S-1320S.

3. Keys A, Menotti A, Aravanis C, et al. (1984) The seven countries study: 2,289 deaths in 15 years. Prev Med 13, $141-154$.

4. Tunstall-Pedoe H, Kuulasmaa K, Mahonen M, et al. (1999) Contribution of trends in survival and coronary-event rates to changes in coronary heart disease mortality: 10-year results from 37 WHO MONICA project populations. Monitoring trends and determinants in cardiovascular disease. Lancet 353, 1547-1557.

5. de Lorgeril M, Salen P, Martin JL, et al. (1999) Mediterranean diet, traditional risk factors, and the rate of cardiovascular complications after myocardial infarction: final report of the Lyon Diet Heart Study. Circulation 99, 779-785.

6. Mozaffarian D, Ascherio A, Hu FB, et al. (2005) Interplay between different polyunsaturated fatty acids and risk of coronary heart disease in men. Circulation 111, 157-164.

7. Rioux V \& Legrand P (2007) Saturated fatty acids: simple molecular structures with complex cellular functions. Curr Opin Clin Nutr Metab Care 10, 752-758.

8. Hoffman R \& Gerber M (2012) The Mediterranean Diet: Health \& Science. Oxford: Wiley-Blackwell.

9. Tresserra-Rimbau A, Medina-Remon A, Perez-Jimenez J, et al. (2013) Dietary intake and major food sources of polyphenols in a Spanish population at high cardiovascular risk: the PREDIMED study. Nutr Metab Cardiovasc Dis 23, 953-959.

10. Covas MI, Nyyssonen K, Poulsen HE, et al. (2006) The effect of polyphenols in olive oil on heart disease risk factors: a randomized trial. Ann Intern Med 145, 333-341.

11. Covas MI, Gambert P, Fito M, et al. (2010) Wine and oxidative stress: up-to-date evidence of the effects of moderate wine consumption on oxidative damage in humans. Atherosclerosis 208, 297-304.

12. Ma Q (2010) Transcriptional responses to oxidative stress: pathological and toxicological implications. Pharmacol Ther 125, 376-393.

13. Leonarduzzi G, Sottero B \& Poli G (2010) Targeting tissue oxidative damage by means of cell signaling modulators: the antioxidant concept revisited. Pharmacol Ther 128, 336-374.

14. Konstantinidou V, Covas MI, Munoz-Aguayo D, et al. (2010) In vivo nutrigenomic effects of virgin olive oil polyphenols within the frame of the Mediterranean diet: a randomized controlled trial. FASEB J 24, 2546-2557.

15. Hollman PC, Cassidy A, Comte B, et al. (2011) The biological relevance of direct antioxidant effects of polyphenols for cardiovascular health in humans is not established. $J$ Nutr 141, 989S-1009S.

16. Menendez JA, Joven J, Aragones G, et al. (2013) Xenohormetic and anti-aging activity of secoiridoid polyphenols present in extra virgin olive oil: a new family of gerosuppressant agents. Cell Cycle 12, 555-578.

17. Grossi C, Rigacci S, Ambrosini S, et al. (2013) The polyphenol oleuropein aglycone protects TgCRND8 mice against Ass plaque pathology. PLOS ONE 8, e71702.

18. Babu PV, Liu D \& Gilbert ER (2013) Recent advances in understanding the anti-diabetic actions of dietary flavonoids. J Nutr Biochem 24, 1777-1789.

19. Romagnolo DF \& Selmin OI (2012) Flavonoids and cancer prevention: a review of the evidence. J Nutr Gerontol Geriatr 31, 206-238.
20. Menendez JA, Vazquez-Martin A, Garcia-Villalba R, et al. (2008) tabAnti-HER2 (erbB-2) oncogene effects of phenolic compounds directly isolated from commercial Extra-Virgin Olive Oil (EVOO). BMC Cancer 8, 377.

21. Buck K, Zaineddin AK, Vrieling A, et al. (2010) Meta-analyses of lignans and enterolignans in relation to breast cancer risk. Am J Clin Nutr 92, 141-153.

22. Nadtochiy SM \& Redman EK (2011) Mediterranean diet and cardioprotection: the role of nitrite, polyunsaturated fatty acids, and polyphenols. Nutrition 27, 733-744.

23. Kushi LH, Lenart EB \& Willett WC (1995) Health implications of Mediterranean diets in light of contemporary knowledge. 2. Meat, wine, fats, and oils. Am J Clin Nutr 61, 1416S-1427S

24. Kushi LH, Lenart EB \& Willett WC (1995) Health implications of Mediterranean diets in light of contemporary knowledge. 1. Plant foods and dairy products. Am J Clin Nutr 61, 1407S-1415S.

25. Gerber M (2001) The comprehensive approach to diet: a critical review. J Nutr 131, 3051S-3055S.

26. Trichopoulou A, Kouris-Blazos A, Wahlqvist ML, et al. (1995) Diet and overall survival in elderly people. BMJ 311, 1457-1460.

27. Trichopoulou A, Costacou T, Bamia C, et al. (2003) Adherence to a Mediterranean diet and survival in a Greek population. N Engl J Med 348, 2599-2608.

28. Hoffman R \& Gerber M (2013) Evaluating and adapting the Mediterranean diet for non-Mediterranean populations: a critical appraisal. Nutr Rev 71, 573-584.

29. Bos MB, de Vries JH, Feskens EJ, et al. (2010) Effect of a high monounsaturated fatty acids diet and a Mediterranean diet on serum lipids and insulin sensitivity in adults with mild abdominal obesity. Nutr Metab Cardiovasc Dis 20, 591-598.

30. Esposito K, Marfella R, Ciotola M, et al. (2004) Effect of a Mediterranean-style diet on endothelial dysfunction and markers of vascular inflammation in the metabolic syndrome: a randomized trial. JAMA 292, 1440-1446.

31. Estruch R, Ros E, Salas-Salvado J, et al. (2013) Primary prevention of cardiovascular disease with a Mediterranean diet. $N$ Engl J Med 368, 1279-1290.

32. Vincent-Baudry S, Defoort C, Gerber M, et al. (2005) The Medi-RIVAGE study: reduction of cardiovascular disease risk factors after a 3-mo intervention with a Mediterraneantype diet or a low-fat diet. Am J Clin Nutr 82, 964-971.

33. Hill AB (1965) The environment and disease: association or causation? Proc $R$ Soc Med 58, 295-300.

34. World Cancer Research Fund/American Institute for Cancer Research (2007) Food, Nutrition, Physical Activity, and the Prevention of Cancer: A Global Perspective. Washington, DC: AICR.

35. Sofi F, Abbate R, Gensini GF, et al. (2011) Accruing evidence on benefits of adherence to the Mediterranean diet on health: an updated systematic review and meta-analysis. Am J Clin Nutr 92, 1189-1196.

36. Bertoia ML, Triche EW, Michaud DS, et al. (2014) Mediterranean and Dietary Approaches to Stop Hypertension dietary patterns and risk of sudden cardiac death in postmenopausal women. Am J Clin Nutr 99, 344-351.

37. Zazpe I, Sanchez-Tainta A, Toledo E, et al. (2014) Dietary patterns and total mortality in a Mediterranean cohort: the SUN project. J Acad Nutr Diet 114, 37-47.

38. Lopez-Garcia E, Rodriguez-Artalejo F, Li TY, et al. (2014) The Mediterranean-style dietary pattern and mortality among men and women with cardiovascular disease. Am J Clin Nutr 99, 172-180. 
39. Buckland G, Agudo A, Travier N, et al. (2011) Adherence to the Mediterranean diet reduces mortality in the Spanish cohort of the European Prospective Investigation into Cancer and Nutrition (EPIC-Spain). Br J Nutr 106, 1581-1591.

40. Knoops KT, de Groot LC, Kromhout D, et al. (2004) Mediterranean diet, lifestyle factors, and 10-year mortality in elderly European men and women: the HALE project. JAMA 292, 1433-1439.

41. Martinez-Gonzalez MA, de la Fuente-Arrillaga C, NunezCordoba JM, et al. (2008) Adherence to Mediterranean diet and risk of developing diabetes: prospective cohort study. BMJ 336, 1348-1351.

42. Salas-Salvado J, Bullo M, Babio N, et al. (2011) Reduction in the incidence of type 2 diabetes with the Mediterranean diet: results of the PREDIMED-Reus nutrition intervention randomized trial. Diabetes Care 34, 14-19.

43. Salas-Salvado J, Bullo M, Estruch R, et al. (2014) Prevention of diabetes with Mediterranean diets: a subgroup analysis of a randomized trial. Ann Intern Med 160, 1-10.

44. Koloverou E, Esposito K, Giugliano D, et al. (2014) The effect of Mediterranean diet on the development of type 2 diabetes mellitus: a meta-analysis of 10 prospective studies and 136,846 participants. Metabolism 63, 903-911.

45. Schwingshackl L, Missbach B, Konig J, et al. (2015) Adherence to a Mediterranean diet and risk of diabetes: a systematic review and meta-analysis. Public Health Nutr 18, 1292-1299.

46. Li WQ, Park Y, Wu JW, et al. (2014) Index-based dietary patterns and risk of head and neck cancer in a large prospective study. Am J Clin Nutr 99, 559-566.

47. Turati F, Trichopoulos D, Polesel J, et al. (2014) Mediterranean diet and hepatocellular carcinoma. J Hepatol 60, 606-611.

48. Praud D, Bertuccio P, Bosetti C, et al. (2014) Adherence to the Mediterranean diet and gastric cancer risk in Italy. Int J Cancer 134, 2935-2941.

49. Buckland G, Agudo A \& Lujan L (2010) Adherence to a Mediterranean diet and risk of gastric adenocarcinoma within the European Prospective Investigation into Cancer and Nutrition (EPIC) cohort study. Am J Clin Nutr 91, 381-390.

50. Buckland G, Ros MM, Roswall N, et al. (2014) Adherence to the Mediterranean diet and risk of bladder cancer in the EPIC cohort study. Int J Cancer 134, 2504-2511.

51. Bessaoud F, Daures JP \& Gerber M (2008) Dietary factors and breast cancer risk: a case control study among a population in Southern France. Nutr Cancer 60, 177-187.

52. Cottet V, Touvier M, Fournier A, et al. (2009) Postmenopausal breast cancer risk and dietary patterns in the E3N-EPIC prospective cohort study. Am J Epidemiol 170, 1257-1267.

53. Trichopoulou A, Bamia C, Lagiou P, et al. (2010) Conformity to traditional Mediterranean diet and breast cancer risk in the
Greek EPIC (European Prospective Investigation into Cancer and Nutrition) cohort. Am J Clin Nutr 92, 620-625.

54. Couto E, Sandin S, Lof M, et al. (2013) Mediterranean dietary pattern and risk of breast cancer. PLOS ONE 8, e55374.

55. Buckland G, Travier N, Barricarte A, et al. (2012) Olive oil intake and $\mathrm{CHD}$ in the European Prospective Investigation into Cancer and Nutrition Spanish cohort. Br J Nutr $\mathbf{1 0 8}$, 2075-2082.

56. Buckland G, Mayen AL, Agudo A, et al. (2012) Olive oil intake and mortality within the Spanish population (EPICSpain). Am J Clin Nutr 96, 142-149.

57. Misirli G, Benetou V, Lagiou P, et al. (2012) Relation of the traditional Mediterranean diet to cerebrovascular disease in a Mediterranean population. Am J Epidemiol 176, $1185-1192$.

58. Buckland G, Travier N, Agudo A, et al. (2012) Olive oil intake and breast cancer risk in the Mediterranean countries of the European Prospective Investigation into Cancer and Nutrition study. Int J Cancer 131, 2465-2469.

59. Berr C, Portet F, Carriere I, et al. (2009) Olive oil and cognition: results from the three-city study. Dement Geriatr Cogn Disord 28, 357-364.

60. FAO (2010) Fats and Fatty Acids in Human Nutrition. Report of an Expert Consultation. FAO Food and Nutrition Paper no. 91. Rome: FAO.

61. AFSSA (2010) Lipides: Apports nutritionnels conseillés (Fat: recommended dietary allowances).

62. Beunza JJ, Toledo E, Hu FB, et al. (2010) Adherence to the Mediterranean diet, long-term weight change, and incident overweight or obesity: the Seguimiento Universidad de Navarra (SUN) cohort. Am J Clin Nutr 92, 1484-1493.

63. Schwarzfuchs D, Golan R \& Shai I (2012) Four-year followup after two-year dietary interventions. $N$ Engl J Med 367, $1373-1374$.

64. Harland JI (2009) An assessment of the economic and heart health benefits of replacing saturated fat in the diet with monounsaturates in the form of rapeseed (canola) oil. Nutr Bull 34, 174-184.

65. Samieri C, Sun Q, Townsend MK, et al. (2013) The association between dietary patterns at midlife and health in aging: an observational study. Ann Intern Med 159, 584-591.

66. Scarmeas N, Luchsinger JA, Schupf N, et al. (2009) Physical activity, diet, and risk of Alzheimer disease. JAMA 302, 627-637.

67. Gerber PJ, Steinfeld H, Henderson B, et al. (2013) Tackling Climate Change Through Livestock - A Global Assessment of Emissions and Mitigation Opportunities. Rome: Food and Agriculture Organization of the United Nations (FAO).

68. Tessier S \& Gerber M (2005) Comparison between Sardinia and Malta: the Mediterranean diet revisited. Appetite $\mathbf{4 5}$, 121-126. 